\title{
Development and Validation of UV Spectrophotometric Method for Simultaneous Estimation of Pregabalin and Etoricoxib in Bulk and Pharmaceutical Dosage Form and the Extension of the Developed Colorimetric Method for Estimation of Pregabalin using Smartphone Application
}

\author{
Nirupa Koshti ${ }^{1}$, Rajashree Mashru ${ }^{2}$ \\ ${ }^{1,2}$ Faculty of Pharmacy, G. H. Patel Building, Donor`s Plaza, Fateh Ganj, The M.S. University of Baroda, \\ Vadodara, Gujarat, India \\ Corresponding Author: Rajashree Mashru
}

\begin{abstract}
A simple, sensitive, accurate, precise and reproducible method has been developed for simultaneous estimation of Pregabalin and Etoricoxib in bulk and pharmaceutical dosage form (bilayer tablet). In the method, the methanol and phosphate buffer $(\mathrm{pH}$ 7.2) were used as solvent as the drugs could not be extracted from bilayer tablet with single organic solvent. Also, pregabalin is not having chromophore, so it does not show absorbance in UV range. So here the pregabalin was derivatized using ethanolic ninhydrin which shows absorption maximum at $576 \mathrm{~nm}$. Etoricoxib shows the absorption maximum at $284 \mathrm{~nm}$. Beer Lambert's law was obeyed over a concentration range of $2-10 \mu \mathrm{g} / \mathrm{ml}$ for Pregabalin $\left(\mathrm{r}^{2}=0.9991\right) \& 4-24 \mu \mathrm{g} / \mathrm{ml}$ for Etoricoxib $\left(r^{2}=0.9998\right)$. The developed method was successfully applied for the estimation of Pregabalin and Etoricoxib in commercial product bilayer tablet. The assay was found to be 99.77 and $99.96 \%$ for Pregabalin and Etoricoxib respectively. The developed method has been validated with respect to linearity, range, accuracy \& precision. Also, the developed colorimetric method was extended for the estimation of Pregabalin using mobile phone/ smartphone application and was successfully used for the assay of pharmaceutical dosage form.
\end{abstract}

Keywords: Pregabalin, Etoricoxib, Ninhydrin, UV spectrophotometric, Bilayer tablet, PhotoMetrix

\section{INTRODUCTION}

Pregabalin is chemically (3S)-3(amino methyl)-5-methylhexanoic acid. ${ }^{[1]}$ It is structurally similar to gammaaminobutyric acid (GABA) - an inhibitory neurotransmitter. [2] The structure of Pregabalin is shown in the Figure 1. [3] Pregabalin is indicated for the management of neuropathic pain associated with diabetic peripheral neuropathy, postherpetic neuralgia, fibromyalgia, neuropathic pain associated with spinal cord injury, and as adjunctive therapy for the treatment of partial-onset seizures in patients 1 month of age and older. ${ }^{[2]}$

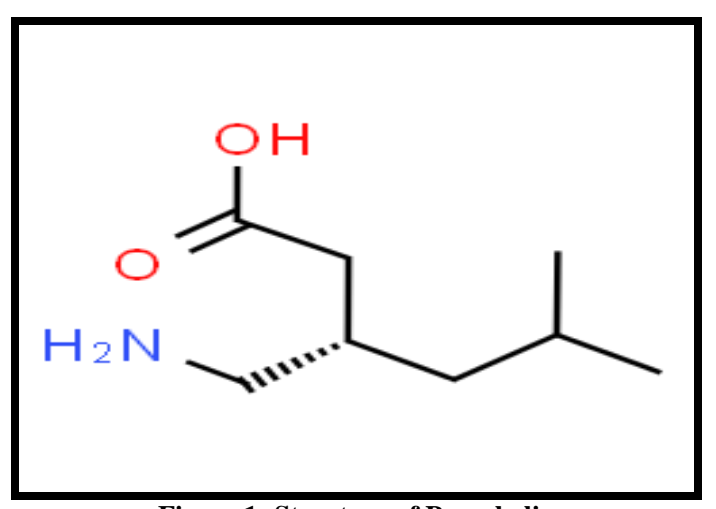

Figure 1: Structure of Pregabalin 
Nirupa Koshti et.al. Development and validation of UV spectrophotometric method for simultaneous estimation of pregabalin and etoricoxib in bulk and pharmaceutical dosage form and the extension of the developed colorimetric method for estimation of pregabalin using smartphone application.

Etoricoxib is chemically 5-chloro-2(6-methylpyridin-3-yl)-3-(4-

methylsulfonylphenyl) pyridine. ${ }^{[4]}$ It is a synthetic, nonsteroidal anti-inflammatory drug (NSAID) and COX 2 selective inhibitor. ${ }^{[5]}$ The structure of etoricoxib is shown in the figure 2. ${ }^{[6]}$ Current therapeutic indications of Etoricoxib are treatment of rheumatoid arthritis, osteoarthritis, ankylosing spondylitis, chronic low back pain, acute pain and gout. ${ }^{[5]}$

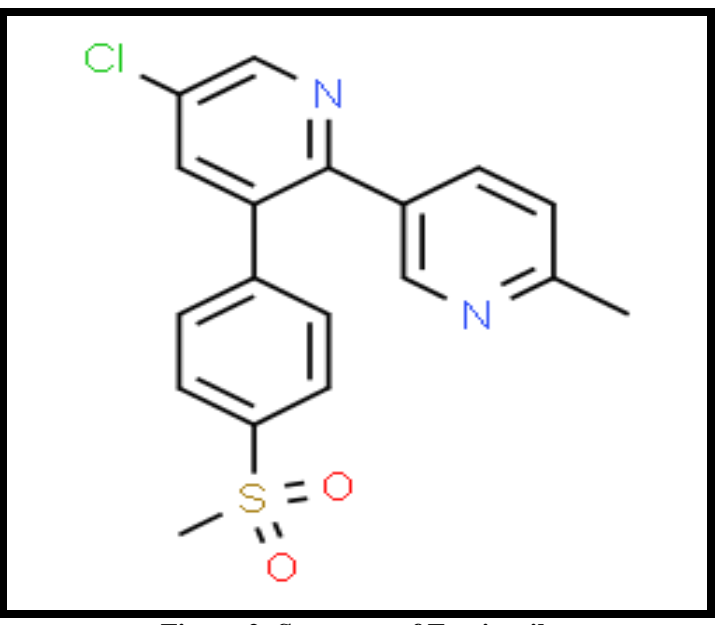

Figure 2: Structure of Etoricoxib

In November,2019, the CDSCO has approved the combination of these two drugs as a bilayer tablet for the treatment of chronic low back pain associated with neuropathic component. [7] Various analytical methods are reported for the estimation of individual drug as well as in combination with other drugs. But there is only one UV- Spectrophotometric method reported for estimation of this combination which is without derivatization of Pregabalin and is based on standard addition method. ${ }^{[8]}$

In this study, a simple, precise, accurate and sensitive UVspectrophotometric method was developed for simultaneous estimation of Pregabalin and Etoricoxib which is without addition of standard drug. There were two major challenges in the development of the method. The first is that, as Pregabalin is having no chromophoric group, it doesn't show absorbance in the UV range, therefore it requires the derivatization. The second is the extraction of drugs from the pharmaceutical formulation. As the formulation is bilayer tablet, where the pregabalin is prolonged release, the drug is trapped in polymer. So could not be extracted with single organic solvent. These challenges were overcome by derivatizing the pregabalin with Ninhydrin and by extracting the drug in the mixture of organic solvent and phosphate buffer.

Also, the developed colorimetric method of Pregabalin was extended for the estimation of drug by the mobile phone/smart phone application. Smartphone-based colorimetry has been gaining relevance because of the widespread advancement of devices with increasing computational power, their relatively low cost and portable designs with user-friendly interfaces, and their compatibility with data acquisition. ${ }^{[9]}$ Various methods has been reported for the estimation of drugs by using smart phone application in which mostly the RGB (Red, Blue and Green) principle has been used. ${ }^{[10-13]}$ In this study, the mobile phone application, called PhotoMetrix, which employs the techniques of simple linear correlation for univariate analysis and principal components analysis (PCA) for multivariate exploratory analysis was used. [14] This PhotoMetrix application is available free in Google Play Store. ${ }^{[14]}$ The method was based on the detection of colour intensities and the evaluation of relationship between measured colour and concentration of sample. ${ }^{[10]}$

\section{MATERIALS \& METHODS Apparatus and Software:}

Shimadzu UV-1700 double beam spectrophotometer connected to a computer with Shimadzu UV-Probe 2.10 software installed was used for all the spectrophotometric measurements. The absorbance spectra of the reference and test solutions were carried out in $1 \mathrm{~cm}$ quartz cells over the range of $200-800 \mathrm{~nm}$. The samples were weighed on an electronic balance $(A \times 120)$ by Shimadzu. Smart phone 
Nirupa Koshti et.al. Development and validation of UV spectrophotometric method for simultaneous estimation of pregabalin and etoricoxib in bulk and pharmaceutical dosage form and the extension of the developed colorimetric method for estimation of pregabalin using smartphone application.

having application PhotoMetrix was used to take images.

\section{Chemicals and Reagents:}

Pregabalin and Etoricoxib (API) were obtained from Zydus Cadila Healthcare Limited as gift samples. Nucoxia PG bilayer tablet was purchased from local medical store.

Preparation of Ethanolic Ninhydrin solution $(3 \% \mathrm{~W} / \mathrm{V})$ : $3 \mathrm{gm}$ of Ninhydrin was dissolved in 95 volume of ethanol and 5 volumes of Glacial acetic acid.

Preparation of phosphate buffer (pH 7.2): $50 \mathrm{ml}$ of $0.2 \mathrm{M}$ potassium dihydrogen phosphate was placed in $200 \mathrm{ml}$ volumetric flask. To that $34.7 \mathrm{ml}$ of $0.2 \mathrm{M} \mathrm{NaOH}$ was added and volume was made up to the mark with water.

Methanol was used as diluent.

(All chemicals used in the present study were of analytical grade.)

\section{Preparation of standard stock solution:}

$5 \mathrm{mg}$ of Pregabalin and Etoricoxib was weighed accurately and transferred into separate $50 \mathrm{ml}$ volumetric flask. To each flask $10 \mathrm{ml}$ of methanol was added and shaken well. Then $20 \mathrm{ml}$ of phosphate buffer ( $\mathrm{pH}$ 7.2) was added and sonicated for $15 \mathrm{~min}$. Then volume was made up to $50 \mathrm{ml}$ with phosphate buffer. This will give the conc. of $100 \mu \mathrm{g} / \mathrm{ml}$ of Pregabalin and Etoricoxib.

\section{Preparation of sample solution:}

20 tablets of formulation (Nucoxia PG) were accurately weighed and powdered. An amount of powder equivalent to $5 \mathrm{mg}$ of Etoricoxib was weighed and transferred into $50 \mathrm{ml}$ volumetric flask. 10 $\mathrm{ml}$ of methanol was added to that and shaken well. Then $20 \mathrm{ml}$ of phosphate buffer ( $\mathrm{pH}$ 7.2) was added and sonicated for 15 minutes. Then solution was made up to the mark with buffer and filtered. This will contain $100 \mu \mathrm{g} / \mathrm{ml}$ of Etoricoxib and 125 $\mu \mathrm{g} / \mathrm{ml}$ of Pregabalin.

Selection of wavelength for Etoricoxib:

$1 \mathrm{ml}$ of the stock solution of Etoricoxib was transferred into $10 \mathrm{ml}$ of volumetric flask and was made up to the mark with methanol. The resulting solution was then scanned between 200-400 nm. The wavelength corresponding to maximum absorbance was found to be $284 \mathrm{~nm}$.

\section{Selection of wavelength for Pregabalin:}

Pregabalin doesn't show absorbance in UV region, even at $100 \mu \mathrm{g} / \mathrm{ml}$ concentration. Therefore, it is derivatized using Ninhydrin. For preliminary test, to 1 $\mathrm{ml}$ of the stock solution, $1.5 \mathrm{ml}$ of $1 \%$ ethanolic ninhydrin solution was added and heated for $5 \mathrm{~min}$ at $60^{\circ} \mathrm{C}$. The solution turns purple which was scanned between 400-800 $\mathrm{nm}$. The wavelength corresponding to maximum absorbance was found to be 576 $\mathrm{nm}$.

\section{Optimization of the colorimetric method:}

To achieve the optimum conditions for this method, the following parameters were studied by keeping other parameters constant.

\section{Optimization of Concentration of Ninhydrin solution:}

To $1 \mathrm{ml}$ stock solution of Pregabalin, $1 \mathrm{ml}$ of different conc. (1-5\%) of ninhydrin was added. The reaction mixtures were heated for $10 \mathrm{~min}$ on a water bath at $60^{\circ} \mathrm{C}$. The coloured product was diluted up to 10 $\mathrm{ml}$ with methanol and the absorbance was measured against a reagent blank at $576 \mathrm{~nm}$. The results showed that the highest absorbance was obtained with $3 \%$ of ninhydrin solution (Figure 3).

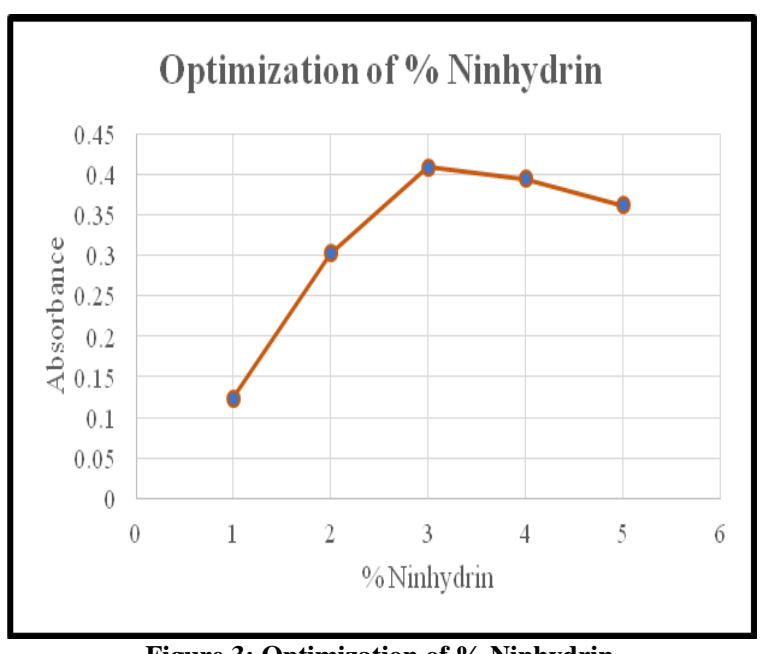

Figure 3: Optimization of \% Ninhydrin 
Nirupa Koshti et.al. Development and validation of UV spectrophotometric method for simultaneous estimation of pregabalin and etoricoxib in bulk and pharmaceutical dosage form and the extension of the developed colorimetric method for estimation of pregabalin using smartphone application.

\section{Optimization of Ninhydrin Volume:}

To $1 \mathrm{ml}$ stock solution of Pregabalin, different volumes $(0.2-2.5 \mathrm{ml})$ of $3 \%$ Ninhydrin were added. The reaction mixtures were heated for $10 \mathrm{~min}$ on a water bath at $60^{\circ} \mathrm{C}$. The coloured product was diluted up to $10 \mathrm{ml}$ with methanol and the absorbance was measured against a reagent blank at $576 \mathrm{~nm}$. The results showed that the highest absorbance was obtained with 2 $\mathrm{ml}$ of ninhydrin solution (Figure 4).

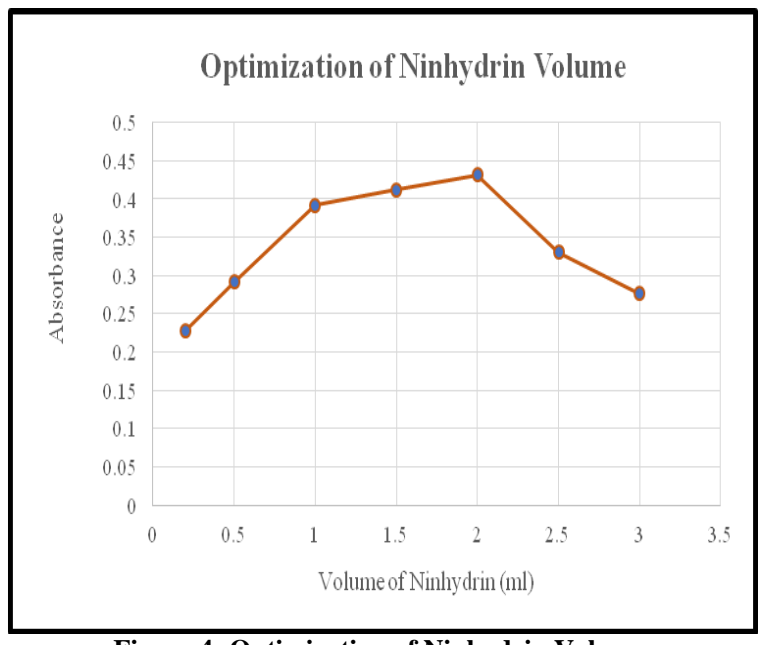

Figure 4: Optimization of Ninhydrin Volume

\section{Optimization of Temperature:}

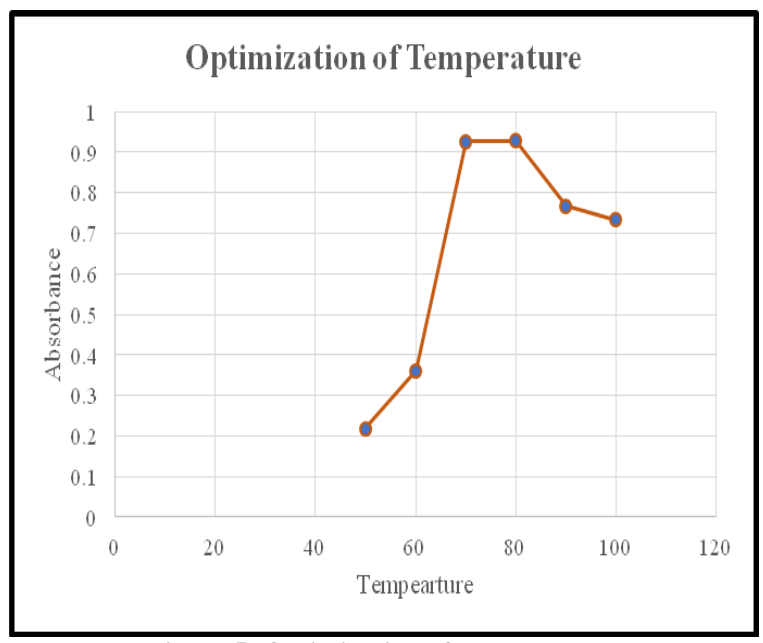

Figure 5: Optimization of Temperature

To $1 \mathrm{ml}$ stock solution of Pregabalin, $2 \mathrm{ml}$ of ninhydrin solution $(3 \% \mathrm{w} / \mathrm{v})$ was added. The reaction mixtures were heated for $10 \mathrm{~min}$ at $50-100^{\circ} \mathrm{C}$. The coloured product was diluted up to $10 \mathrm{ml}$ with methanol and the absorbance was measured against a reagent blank at $576 \mathrm{~nm}$. The results showed that the highest absorbance was obtained at $70 \pm 2^{\circ} \mathrm{C}$ (Figure 5). The developed colour was stable for $48 \mathrm{~h}$.

\section{Optimization of Heating time:}

To $1 \mathrm{ml}$ stock solution of Pregabalin, $2 \mathrm{ml}$ of $3 \% \mathrm{w} / \mathrm{v}$ of ninhydrin solution was added. The reaction mixture was heated on a water bath at $70^{\circ} \mathrm{C}$ for $5-45 \mathrm{~min}$. The coloured product was diluted up to $10 \mathrm{ml}$ with methanol and the absorbance was measured against a reagent blank at $576 \mathrm{~nm}$. The results showed that the highest absorbance was obtained with $25 \mathrm{~min}$ (Figure 6).

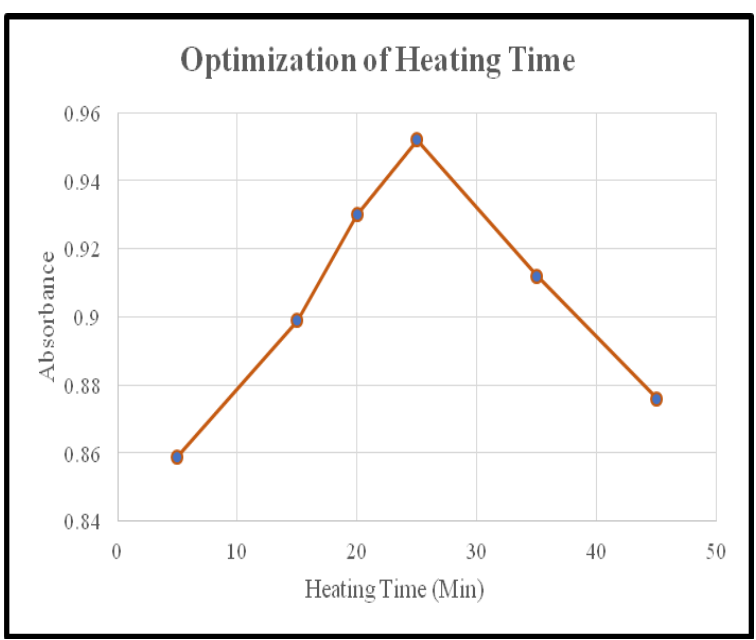

Figure 6: Optimization of Heating Time

The table 1 describes the optimized value of all 4 parameters.

Table 1: Optimized conditions for the colorimetric estimation of Pregabalin

\begin{tabular}{|l|l|}
\hline Parameter & Optimized value \\
\hline$\%$ Ninhydrin & $3 \%$ \\
\hline Volume of Ninhydrin & $2 \mathrm{ml}$ \\
\hline Temperature & $70^{\circ} \mathrm{C}$ \\
\hline Heating time & $25 \mathrm{~min}$ \\
\hline
\end{tabular}

\section{Reaction Mechanism: ${ }^{[15]}$}

Reaction of ninhydrin with amines, alpha amino acids, peptides, and proteins yields an aldehyde with one carbon atom less than the alpha-amino acid; and carbon dioxide in stoichiometric amounts and varying amounts of ammonia, hydrindantin and a chromophoric compound known as Ruhemann's Purple (2-(3-hydroxy-1-oxo1H-inden-2-ylimino)-2Hindene-1,3-dione). This pigment serves as the basis of detection and quantitative estimation of alpha-amino acids. Mechanism proposed (Figure 7) for 
Nirupa Koshti et.al. Development and validation of UV spectrophotometric method for simultaneous estimation of pregabalin and etoricoxib in bulk and pharmaceutical dosage form and the extension of the developed colorimetric method for estimation of pregabalin using smartphone application.

the reaction involves removal of a water molecule from ninhydrin hydrate 1 to generate 1,2,3-indantrione 2 in the first step, which then, forms a Schiff's base with the amino group of pregabalin resulting in the ketamine 3. Removal of the aldehyde
RCHO generates an intermediate amine 4 (2-aminol,3-indandione). Condensation of this intermediate amine with another molecule of ninhydrin follows to form the expected chromophore 5 (Ruhemann's Purple).

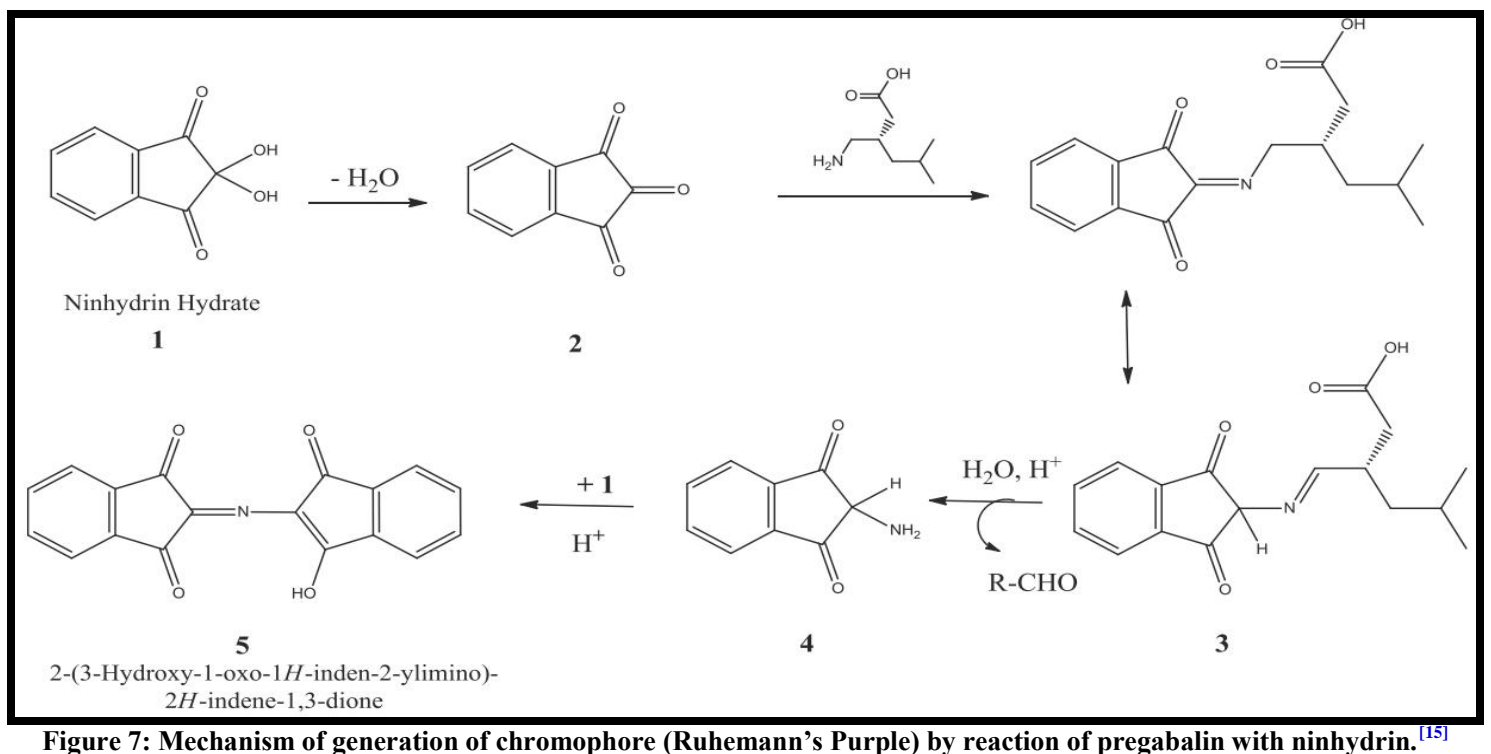

\section{Preparation of calibration graph: Pregabalin:}

Aliquots of standard solution of Pregabalin corresponding to $2-10 \mu \mathrm{g} / \mathrm{ml}$ was taken into $10 \mathrm{ml}$ volumetric flask. To each flask $2 \mathrm{ml}$ of $3 \%$ Ninhydrin solution was added and solution was heated for $25 \mathrm{~min}$ at $70{ }^{\circ} \mathrm{C}$. The solution was allowed to cool at room temperature and then volume was made up to $10 \mathrm{ml}$ with methanol. The absorbance of the solution was measured at $576 \mathrm{~nm}$ against blank.

\section{Etoricoxib:}

Aliquots of standard solution of Etoricoxib corresponding to $4-24 \mu \mathrm{g} / \mathrm{ml}$ was taken into $10 \mathrm{ml}$ volumetric flask and was made up to the mark with methanol. The absorbance of each solution was measured at $284 \mathrm{~nm}$.

The calibration curve was plotted at their corresponding wavelengths.

\section{Analysis of marketed formulation:}

From the prepared sample solution of formulation, $0.6 \mathrm{ml}$ was transferred into $10 \mathrm{ml}$ volumetric flask and was made up to the mark with methanol. The absorbance of solution was determined at $284 \mathrm{~nm}$ for the estimation of Etoricoxib. From the remaining sample solution again $0.6 \mathrm{ml}$ was transferred into $10 \mathrm{ml}$ volumetric flask and treated in the same manner as given for working standard of Pregabalin and absorbance was measured at $576 \mathrm{~nm}$. The absorbance of the drugs was calculated by standard curve method.

\section{ESTIMATION OF PREGABALIN USING SMARTPHONE APPLICATION: Experimental Setup:}

A self-designed box was built in the lab to improve accuracy and precision of the measurements. On the upper side of the box, an LED bulb was fitted to provide consistent incident light source. All the inner side wall of the box were covered with white paper to provide full reflection of the light. The front side is made in a manner that it can be open to insert a cuvette inside the box (Figure 9A). In the front side of the box, a small square shaped hole was made exactly in the middle to allow the camera to take photo of the object placed inside the 
Nirupa Koshti et.al. Development and validation of UV spectrophotometric method for simultaneous estimation of pregabalin and etoricoxib in bulk and pharmaceutical dosage form and the extension of the developed colorimetric method for estimation of pregabalin using smartphone application.

box. Also, A cuvette holder was made from the box. The entire experimental setup is thermocol and was fixed in the middle of illustrated in the figure 8 .

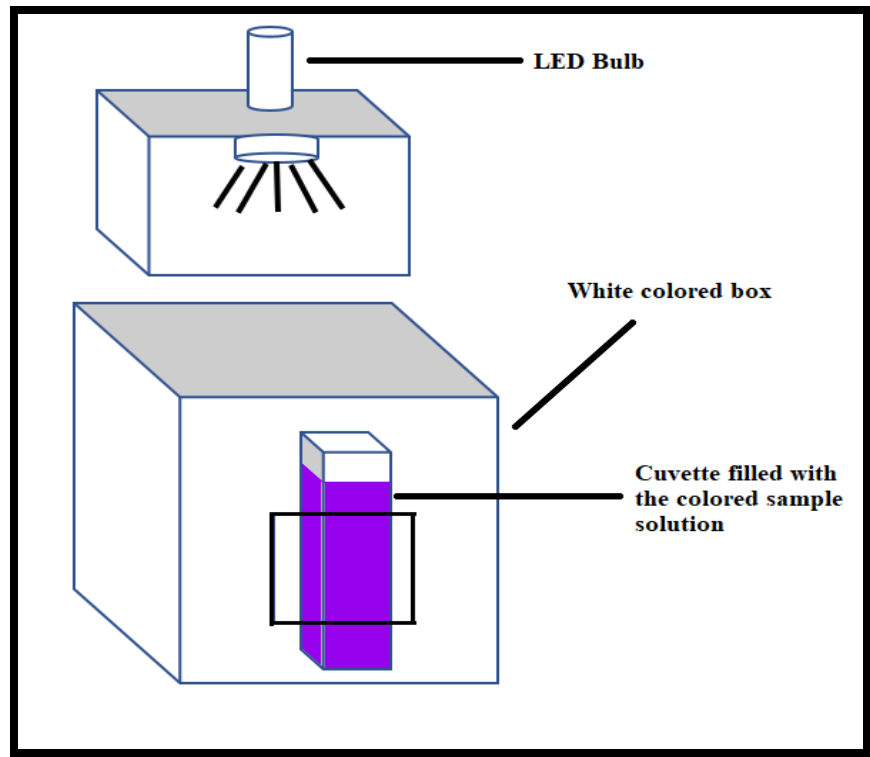

Figure 8: Illustration of experimental setup for image acquisition
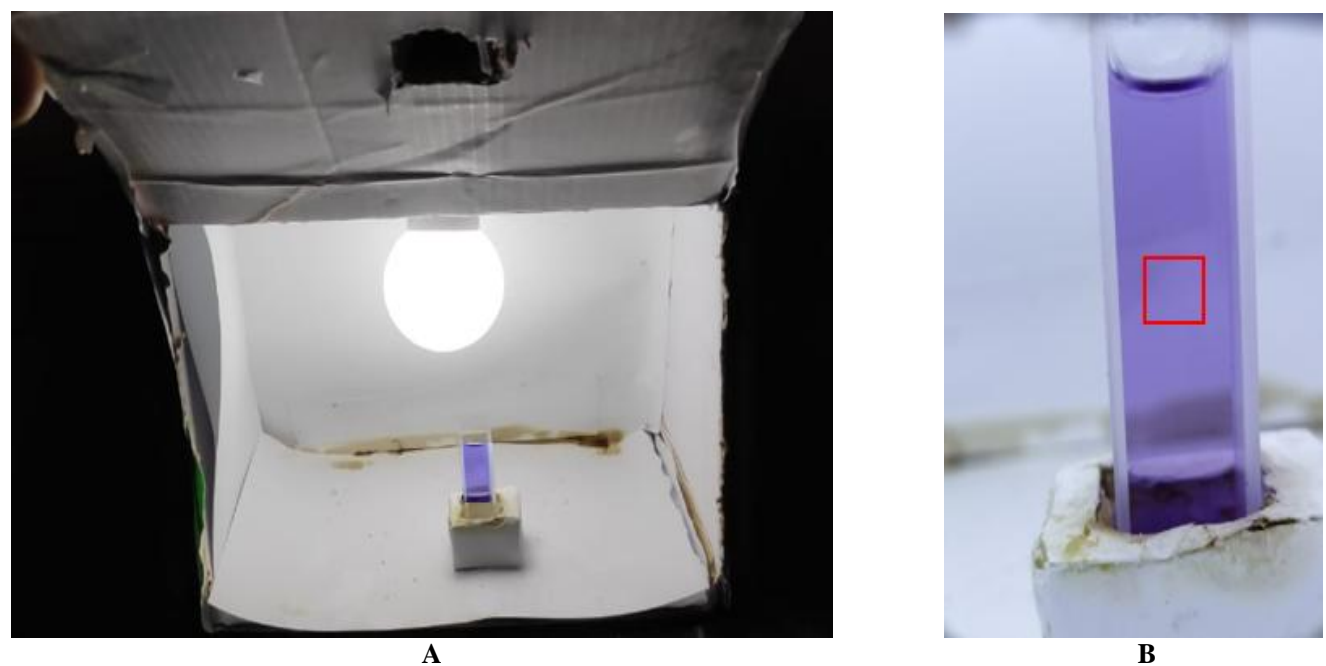

Figure 9: A. Cuvette placed in the arranged setup

B. Image captured by mobile phone camera in the arranged setup

\section{Preparation of calibration graph by smart phone application:}

Aliquots of standard solution of pregabalin corresponding to $2-10 \mu \mathrm{g} / \mathrm{ml}$ was taken into $10 \mathrm{ml}$ volumetric flask. To each flask $2 \mathrm{ml}$ of 3\% Ninhydrin solution was added and solution was heated for $25 \mathrm{~min}$ at $70^{\circ} \mathrm{C}$. The solution was allowed to cool at room temperature and then volume was made up to $10 \mathrm{ml}$ with methanol.

Once the standard solutions were prepared, the images were captured one by one in the PhotoMetrix Pro application. The interface of the application as well as the options to be choose in stepwise manner was shown in the figure 10 . In application first Univariate Analysis, then in Univariate Analysis Vector RGB was selected. Then once you click on calibration, the app will ask about the number of samples. Here, in number of samples 6 was written (1 blank and 5 standards). Then first the blank solution was filled in the cuvette and was inserted in the box and after writing 0 in the concentration section, image was captured by putting the camera at the middle hole of the box. In same manner one by one the image was captured of all standard solution 
Nirupa Koshti et.al. Development and validation of UV spectrophotometric method for simultaneous estimation of pregabalin and etoricoxib in bulk and pharmaceutical dosage form and the extension of the developed colorimetric method for estimation of pregabalin using smartphone application.

in an increasing order of concentration. equation was shown by the application Then the save button was clicked and the itself. calibration graph as well as regression

$\mathbf{A}$

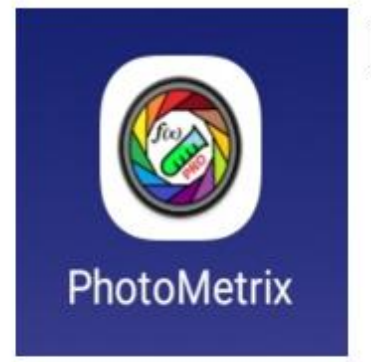

D

PhotoMetrix Univariate Vector RGB Analysis
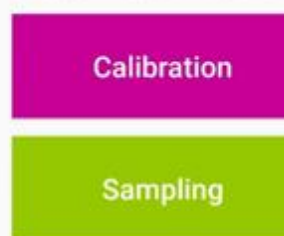

Saved Results

Help
B

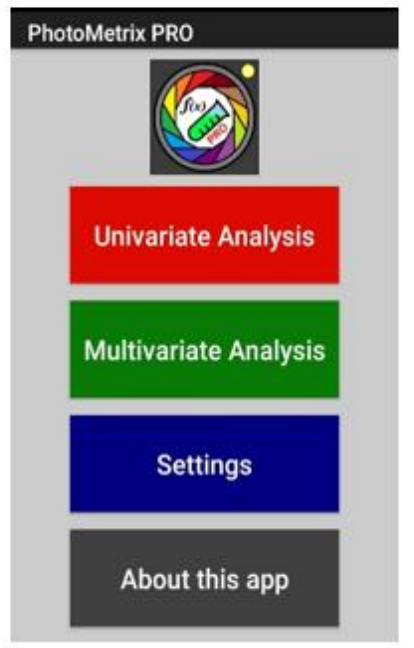

$\mathbf{E}$

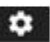

政
Number of samples:

\section{Region of interest:}

Local:

Date:

\section{$17 / 06 / 2021$}

Capture images

Last Calibrations - Tap to select
C

\section{PhotoMetrix}

Univariate Analysis

Multiple channels

Vector RGB

F

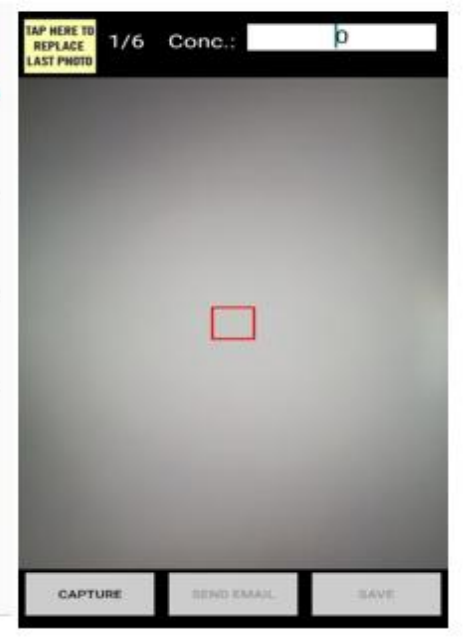

Figure 10: Graphic interface of the PhotoMetrix Application and steps to generate calibration graph in application

Once the regression equation was obtained, the concentration of the sample solution from formulation was estimated. Here, instead of calibration, sampling button was clicked and the image of sample solution prepared for assay was captured in the manner similar to standard solution. Then save button was clicked and the concentration of sample was given by application from the generated calibration graph.

\section{RESULT AND DISCUSSION Method Validation: ${ }^{[16]}$}

\section{Linearity:}

Pregabalin was linear with the concentration range of $2-10 \mu \mathrm{g} / \mathrm{ml}$ at 576 $\mathrm{nm}$ and Etoricoxib showed the linearity in the range of $4-24 \mu \mathrm{g} / \mathrm{ml}$ at $284 \mathrm{~nm}$, by obeying Beer's law (Figure 10 and 11). A calibration curve was plotted between concentration Vs absorbance. The plot was found to be linear and shown in the figure 13 and 14. Also, the statistical data are shown in the table 2. 
Nirupa Koshti et.al. Development and validation of UV spectrophotometric method for simultaneous estimation of pregabalin and etoricoxib in bulk and pharmaceutical dosage form and the extension of the developed colorimetric method for estimation of pregabalin using smartphone application.

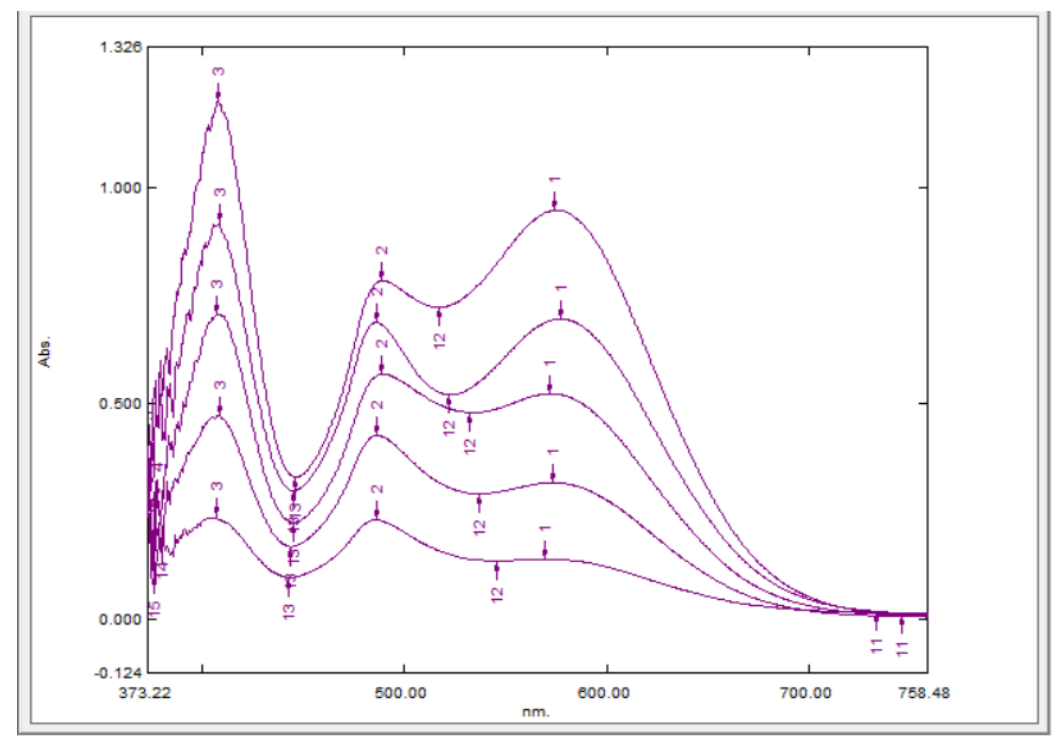

Figure 11: Overlay UV Spectra of Pregabalin $(2-10 \mu \mathrm{g} / \mathrm{ml})$

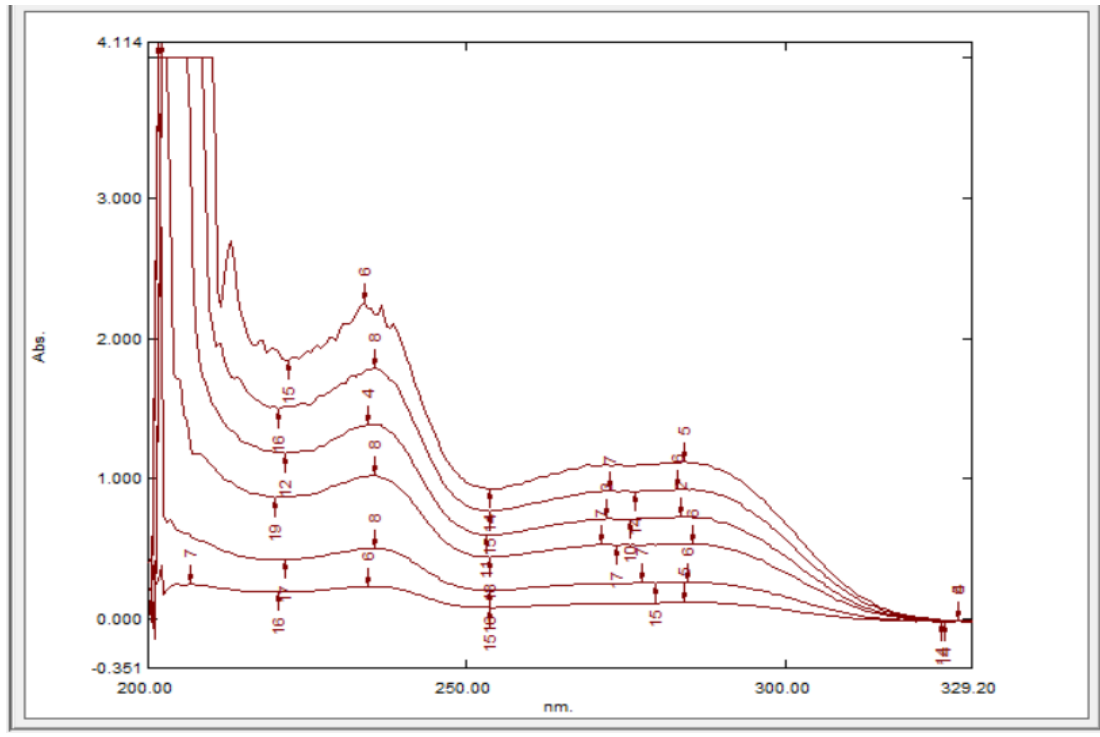

Figure 12: Overlay UV Spectra of Etoricoxib $(4-24 \mu \mathrm{g} / \mathrm{ml})$

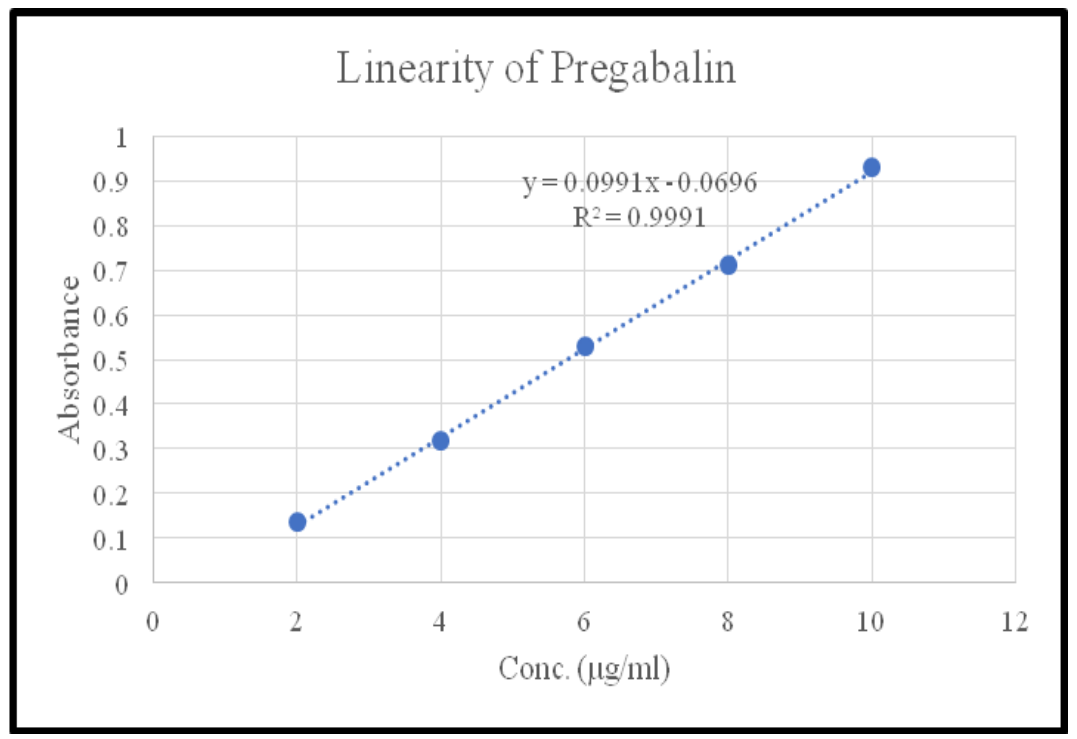

Figure 13: Calibration graph of Pregabalin 
Nirupa Koshti et.al. Development and validation of UV spectrophotometric method for simultaneous estimation of pregabalin and etoricoxib in bulk and pharmaceutical dosage form and the extension of the developed colorimetric method for estimation of pregabalin using smartphone application.

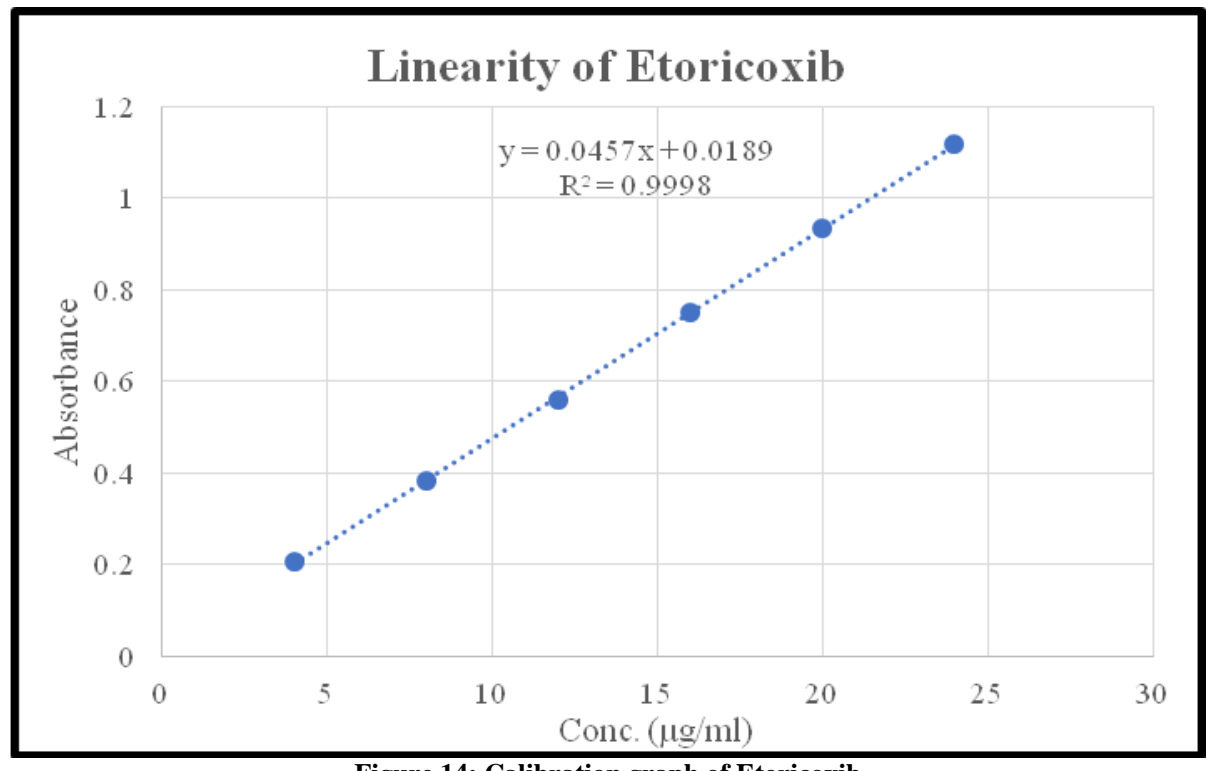

Figure 14: Calibration graph of Etoricoxib

Table 2: Statistical data for the regression equation of the proposed method

\begin{tabular}{|l|l|l|}
\hline Parameter & Pregabalin & Etoricoxib \\
\hline $\begin{array}{l}\text { Analytical wavelength } \\
(\mathrm{nm})\end{array}$ & 576 & 284 \\
\hline Linearity range $(\mu \mathrm{g} / \mathrm{ml})$ & $2-10$ & $4-24$ \\
\hline Regression equation & $0.0991 \mathrm{x}-0.0696$ & $0.0457 \mathrm{x}+0.0189$ \\
\hline Slope & 0.0994 & 0.0446 \\
\hline Intercept coefficient & 0.0718 & 0.0196 \\
\hline $\begin{array}{l}\text { Correlation } \\
\left(\mathrm{R}^{2}\right)\end{array}$ & 0.9991 \\
\hline Limit of detection $(\mu \mathrm{g} / \mathrm{ml})$ & 0.0766 & 0.5674 \\
\hline $\begin{array}{l}\text { Limit of Quantification } \\
(\mu \mathrm{g} / \mathrm{ml})\end{array}$ & 0.2321 & 1.7193 \\
\hline
\end{tabular}

\section{Precision:}

The precision of an analytical method expresses the closeness of agreement between a series of measurements which are obtained by performing multiple samplings of the same homogenous sample under the given conditions of the method. Here, the intraday (Repeatability) and inter-day precision was determined. For that threeconcentration having lower, upper and middle limits of both the drugs were taken and analysed three times on the same day for intra-day precision and on 3 different days for inter-day precision at the same concentration level. The \% RSD was calculated (Table 3 and 4) and was found to be less than 2 .

Table 3: Intraday and Interday precision of Pregabalin

\begin{tabular}{|l|l|l|l|}
\hline \multirow{3}{*}{ Intra day } & Conc. & Mean \pm SD $(\mathbf{n}=\mathbf{3})$ & \%RSD \\
\cline { 2 - 4 } & 2 & $0.136 \pm 0.0012$ & 0.882 \\
\cline { 2 - 4 } & 6 & $0.525 \pm 0.0036$ & 0.686 \\
\cline { 2 - 4 } Inter day & 10 & $0.931 \pm 0.003155$ & 0.333 \\
\cline { 2 - 4 } & 2 & $0.135 \pm 0.001$ & 0.741 \\
\cline { 2 - 4 } & 6 & $0.525 \pm 0.0035$ & 0.667 \\
\cline { 2 - 4 } & 10 & $0.933 \pm 0.0031$ & 0.327 \\
\hline
\end{tabular}

Table 4: Intraday and Interday precision of Etoricoxib

\begin{tabular}{|l|l|l|l|}
\hline \multirow{3}{*}{ Intra day } & Conc. & Mean \pm SD $(\mathbf{n}=\mathbf{3})$ & \%RSD \\
\cline { 2 - 4 } & 12 & $0.209 \pm 0.002$ & 0.957 \\
\cline { 2 - 4 } & 20 & $0.550 \pm 0.0026$ & 0.473 \\
\hline Inter day & 4 & $0.911 \pm 0.0048$ & 0.527 \\
\cline { 2 - 4 } & 12 & $0.211 \pm 0.0018$ & 0.85 \\
\cline { 2 - 4 } & 20 & $0.549 \pm 0.0023$ & 0.419 \\
\hline
\end{tabular}

\section{Accuracy:}

The accuracy of the method was determined by recovery experiments. A known quantity of the pure drug was added to the pre-analysed sample formulation at $80 \%, 100 \%$ and $120 \%$ levels. The recovery studies were carried out and the percentage recovery and percentage relative standard deviation of the percentage recovery were calculated and given in Table 5 .

Table 5: Accuracy data of Pregabalin and Etoricoxib

\begin{tabular}{|l|l|l|l|l|l|l|}
\hline Drug & \% Spiked & Conc. from formulation & Standard conc. added & Conc. recovered & \%recovery \pm SD $(\mathbf{n}=3)$ & \% RSD \\
\hline Pregabalin & 0 & 7.5 & 6 & 6.11 & $101.83 \pm 0.46$ & 0.452 \\
\cline { 2 - 7 } & 100 & 7.5 & 7.5 & 7.55 & $100.66 \pm 0.423$ & 0.42 \\
\cline { 2 - 7 } & 120 & 7.5 & 9 & 9.06 & $100.64 \pm 0.501$ & 0.498 \\
\hline etoricoxib & 0 & 6 & 4.8 & 4.84 & $100.83 \pm 0.456$ & 0.452 \\
\cline { 2 - 7 } & 100 & 6 & 6.2 & 7.89 & $98.16 \pm 0.412$ & 0.42 \\
\cline { 2 - 7 } & 120 & 6 & 7.22 & $100.28 \pm 0.468$ & 0.467 \\
\hline
\end{tabular}


Nirupa Koshti et.al. Development and validation of UV spectrophotometric method for simultaneous estimation of pregabalin and etoricoxib in bulk and pharmaceutical dosage form and the extension of the developed colorimetric method for estimation of pregabalin using smartphone application.

\section{Analysis of the marketed formulation:}

The assay of Pregabalin and Etoricoxib was found to be 99.77 and $99.96 \%$ respectively which is within the acceptance criteria (98-102\%).

Table 6: Assay results of the Marketed Formulation

\begin{tabular}{|l|l|l|l|l|}
\hline Drug & Conc. $(\boldsymbol{\mu g} / \mathbf{m l})$ & Conc. Found $(\boldsymbol{\mu g} / \mathbf{m l})$ & \% Recovery \pm SD $(\mathbf{n}=\mathbf{6})$ & \% RSD \\
\hline Pregabalin & 7.5 & 7.48 & $99.77 \pm 0.436$ & 0.437 \\
\hline Etoricoxib & 6 & 5.998 & $99.96 \pm 0.392$ & 0.392 \\
\hline
\end{tabular}

Estimation of Pregabalin using Smartphone application:

The linearity of the standard pregabalin was taken in the range of 2-10 $\mu \mathrm{g} / \mathrm{ml}$. The calibration curve and regression equation generated by the application was shown in the figure 16. The concentration of sample solution was found to be 7.443 $\mu \mathrm{g} / \mathrm{ml}$ (Nominal $7.5 \mu \mathrm{g} / \mathrm{ml}$ ). The $\%$ assay was found to be $99.24 \%$ which is within the acceptance criteria.

Caliber: 1 Concentration: $0.0 \%$

Caliber: 2 Concentration: $2.0 \%$

Caliber: 3 Concentration: $4.0 \%$

Caliber: 4 Concentration: $6.0 \%$

Caliber: 5 Concentration: $8.0 \%$

Caliber: 6 Concentration: $10.0 \%$

Figure 15: Chart of colour intensity corresponding to the concentration of Pregabalin

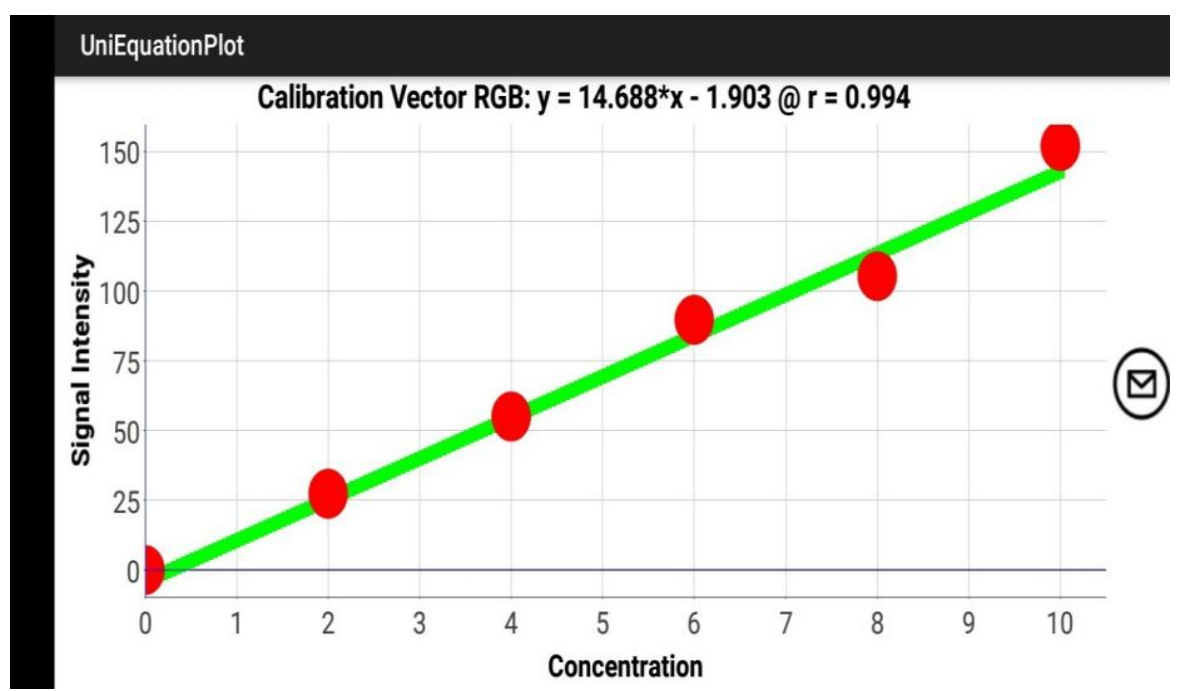

Figure 16: Calibration graph of Pregabalin generated by Photometrix Application

\section{Comparison spectrophotometric \\ between method \\ UV- Smartphone Image Analysis by T-Test:}

Table 7: T-test table for the comparison of UV
spectrophotometric and Smartphone Application method
\begin{tabular}{|l|l|l|}
\hline & Variable 1 & Variable 2 \\
\hline Mean & 99.695 & 99.24 \\
\hline Variance & 0.02587 & 0.28576 \\
\hline Observations & 6 & 6 \\
\hline Pooled Variance & 0.155815 & \\
\hline Hypothesized Mean Difference & 0 & \\
\hline df & 10 & \\
\hline t Stat & 1.996491 & \\
\hline P(T<=t) one-tail & 0.036909 & \\
\hline t Critical one-tail & 1.812461 & \\
\hline $\mathrm{P}(\mathrm{T}<=\mathrm{t})$ two-tail & 0.073818 & \\
\hline t Critical two-tail & 2.228139 & \\
\hline
\end{tabular}

In order to compare two different methods statistically, the Student's t-test was used to analyse the results for the sample and the data are shown in the table 7.

The calculated t-value was smaller than the critical t-value, therefore showing no statistical difference at a $95 \%$ confidence level between UV spectrophotometric and Smartphone Image Analysis.

\section{CONCLUSION}

A simple, precise, accurate and sensitive method was developed for the 
Nirupa Koshti et.al. Development and validation of UV spectrophotometric method for simultaneous estimation of pregabalin and etoricoxib in bulk and pharmaceutical dosage form and the extension of the developed colorimetric method for estimation of pregabalin using smartphone application.

simultaneous estimation of Pregabalin and Etoricoxib. The method was validated according to the ICH guidelines. The method can be used for the routine analysis of the drugs in their pharmaceutical dosage form. Also, the developed colorimetric method was successfully extended for the estimation of Pregabalin using smart phone application. This application can be used as an alternative to sophisticated and high-cost devices in quantitative analysis.

Acknowledgement: None

\section{Conflict of Interest: None}

\section{Source of Funding: None}

Ethical Approval: Approved

\section{REFERENCES}

1. Pregabalin $\mid \mathrm{C} 8 \mathrm{H} 17 \mathrm{NO} 2$ - PubChem [Internet]. [cited 2021 Apr 26]. Available from: https://pubchem.ncbi.nlm.nih.gov/comp ound/Pregabalin

2. Pregabalin | DrugBank Online [Internet]. [cited 2021 Apr 26]. Available from: https://go.drugbank.com/drugs/DB0023 0

3. Pregabalin $|\mathrm{C} 8 \mathrm{H} 17 \mathrm{NO} 2|$ ChemSpider [Internet]. [cited 2021 Apr 26]. Available from: http://www.chemspider.com/ChemicalStructure.4589156.html

4. Etoricoxib | C18H15ClN2O2S PubChem [Internet]. [cited 2021 Apr 26]. Available from: https://pubchem.ncbi.nlm.nih.gov/comp ound/Etoricoxib

5. Etoricoxib | DrugBank Online [Internet]. [cited 2021 Apr 26]. Available from: https://go.drugbank.com/drugs/DB0162 8

6. etoricoxib | C18H15CIN2O2S ChemSpider [Internet]. [cited $2021 \mathrm{Apr}$ 26]. Available from: http://www.chemspider.com/ChemicalStructure.110209.html
7. DCG(I). Fixed dose combinations approved y DCG(I) since 1961 to 31 st Demember 2019. 2019;(1):1-123. Available from: https://cdsco.gov.in/opencms/opencms/s ystem/modules/CDSCO.WEB/elements/ download_file_division.jsp?num_id=NT QyMw==

8. Prakash M, Abirami G, Vetrichelvan T. Method Development And Validation Of Pregabalin And Etoricoxib In Bulk And Pharmaceutical Dosage Form By Uv Spectroscopy (Standard Addition) Method. 2021;10(1):1194-203.

9. Kılıç V, Horzum N, Ertugrul Solmaz M. From Sophisticated Analysis to Colorimetric Determination: Smartphone Spectrometers and Colorimetry. Color Detect. 2020;1-19.

10. Wai MH, Senee K, Wirat R. RGB Colorimetric Method for the Quantitative Analysis of Levocetirizine Tablets. IJPS. 2020; 16(3).

11. Firdaus ML, Aprian A, Meileza N, Hitsmi M, Elvia R, Rahmidar L, et al. Smartphone coupled with a paper-based colorimetric device for sensitive and portable mercury ion sensing. Chemosensors. 2019;7(2).

12. Coutinho MS, Morais CLM, Neves ACO, Menezes FG, Lima KMG. Colorimetric determination of ascorbic acid based on its interfering effect in the enzymatic analysis of glucose: An approach using smartphone image analysis. J Braz Chem Soc. 2017;28(12):2500-5.

13. Moonrungsee N, Pencharee S, Jakmunee J. Colorimetric analyzer based on mobile phone camera for determination of available phosphorus in soil. Talanta [Internet]. 2015;136:204-9. Available from:

http://dx.doi.org/10.1016/j.talanta.2015. 01.024

14. Helfer GA, Magnus VS, Böck FC, Teichmann A, Ferrão MF, Da Costa AB. PhotoMetrix: An application for univariate calibration and principal components analysis using colorimetry 
Nirupa Koshti et.al. Development and validation of UV spectrophotometric method for simultaneous estimation of pregabalin and etoricoxib in bulk and pharmaceutical dosage form and the extension of the developed colorimetric method for estimation of pregabalin using smartphone application.

on mobile devices. J Braz Chem Soc. How to cite this article: Koshti N, Mashru 2017;28(2):328-35.

15. Bali A, Gaur P. A novel method for spectrophotometric determination of pregabalin in pure form and in capsules. Chem Cent J. 2011;5(1):1-7.

16. Agency EM. European Medicines Agency. 2006;2(June 1995):1-15.

R. Development and validation of UV spectrophotometric method for simultaneous estimation of pregabalin and etoricoxib in bulk and pharmaceutical dosage form and the extension of the developed colorimetric method for estimation of pregabalin using smartphone application. International Journal of Research and Review. 2021; 8(6): 387-398. DOI:https://doi.org/10.52403/ijrr.20210649 